\title{
E-CADHERIN DISTRIBUTION AND EPITHELIAL BASEMENT MEMBRANE CHARACTERISTICS OF THE NORMAL HUMAN CONJUNCTIVA AND CORNEA
}

\author{
R. A. H. SCOTT ${ }^{1}$, B. LAUWERYNS ${ }^{1}$, D. M. J. SNEAD ${ }^{2}$, R. J. HAYNES ${ }^{1}$, Y. MAHIDA ${ }^{3}$ and \\ H. S. DUA ${ }^{1}$ \\ Nottingham
}

\begin{abstract}
SUMMARY
The conjunctival mucosa has several similarities to the mucosal immune system of the gut and bronchus. Like the gut and bronchial mucosa, the conjunctiva is capable of inducing tolerance to encountered antigens and possesses a repertoire of $\mathrm{CDB}^{+}$intraepithelial lymphocytes (IELs) bearing the human mucosal lymphocyte-1 antigen (HML-1) which has been shown to be an $\alpha_{E} \beta_{7}$ integrin. The epithelial cells surface ligand for HML-1 is E-cadherin. The distribution of E-cadherin in the normal human conjunctiva and cornea is not known. We investigated E-cadherin distribution in the conjunctiva and cornea by immunohistochemistry. E-cadherin was found to be present in all layers of the conjunctival epithelium but not in corneal epithelium. In the conjunctiva it may act as a ligand for the HML- ${ }^{+}$IELs. The specific location of IELs along the basal cells of the conjunctiva compared with the generalised distribution of $\mathbf{E}$-cadherin through all layers, indicates that factors other than E-cadherin binding determine the distribution of HML-1 ${ }^{+}$IELs. We performed electron microscopy on de-epithelialised conjunctival and corneal samples. We demonstrated the presence of epithelial basement membrane pores in the conjunctiva but not in the cornea. Lymphocyte migration from the substantia propria to the intraepithelial compartment appears to occur through these pores, which may also serve as a conduit for antigen presentation by epithelial antigen presenting cells (APCs) to lymphocytes in the substantia propria.
\end{abstract}

The conjunctival mucosa is in virtually constant contact with airborne antigenic material from the natural environment. Conjunctival allergy to environmental antigens is, however, the exception rather

From: Departments of ${ }^{1}$ Ophthalmology, ${ }^{2}$ Pathology and ${ }^{3}$ Gastroenterology, University Hospital, Queens Medical Centre, Nottingham, UK.

Correspondence to: H. S. Dua, Chair and Professor of Ophthalmology, B floor, South Block, University Hospital, Queens Medical Centre, Nottingham NG7 2UH, UK. than the rule. The gastrointestinal and respiratory tracts are faced with a conceptually similar problem in that they too are constantly exposed to ingested and inhaled antigens. Research over the past 30 years has established an important role for adaptive immune responses in the gut and bronchial mucosa which induce a state of tolerance to encountered antigens. ${ }^{1-5}$ Immunocompetent cells of the mucosal immune system are collectively defined as Mucosa Associated Lymphoid Tissue (MALT) and consist of undifferentiated lymphocytes and macrophages in a loose stromal network covered by lymphoepithelium. ${ }^{4}$ Dendritic cells, Langerhans cells and modified mucosal epithelial cells present antigen to lymphocytes within MALT. Another unique cell population within MALT are the intraepithelial lymphocytes (IELs). Between $80 \%$ and $95 \%$ of IELs are $\mathrm{CD} 8^{+}$ lymphocytes that are distributed along the basolateral surfaces of basal epithelial cells just above the basement membrane. ${ }^{6}$ These cells express the human mucosal lymphocyte-1 (HML-1) antigen, which is an $\alpha_{\mathrm{E}} \beta_{7}$ integrin. ${ }^{6,7}$

Conjunctiva Associated Lymphoid Tissue (CALT) has several similarities to MALT. The conjunctiva is fully equipped to capture, process and present antigen to immunocompetent cells. ${ }^{8}$ Instillation of purified retinal antigens into the conjunctival sac of Lewis rats has been shown to induce a state of tolerance as evidence by an attenuated response to subsequent challenge with these antigens. ${ }^{9}$ Similarly conjunctival instillation of ovalbumin has been demonstrated to induce tolerance in mice with localisation of ovalbumin-specific lymphocytes in the submandibular lymph nodes. ${ }^{10}$ The distribution of $\mathrm{CD}^{+}$and $\mathrm{CD}^{+}$lymphocytes in the epithelium and substantia propria of the human and rat conjunctiva ${ }^{8,11}$ and, more specifically, the distribution of $\mathrm{CD}^{+} \mathrm{HML}^{+}{ }^{+}$IELs in the human conjunctiva 
have been shown to be identical to that found in the gastrointestinal mucosa. ${ }^{8}$

E-cadherin, a tissue-specific intercellular adhesion molecule, is now known to act as the ligand for the HML-1 integrin. ${ }^{7}$ Heterotypic E-cadherin/HML-1 bonds have been demonstrated to bind IELs to the intestinal epithelium and may be responsible for the retention of $\mathrm{CD}^{+}{ }^{+} \mathrm{HML}_{-}{ }^{+}$IELs in the mucosa. ${ }^{7}$ Homotypic E-cadherin/E-cadherin bonds are normally responsible for the integrity of the epithelial layer. This binding is calcium dependent. ${ }^{12,13}$

The purpose of this study was to determine whether this mechanism of IEL/E-cadherin binding was likely to be present in the conjunctiva. We investigated the distribution of E-cadherin in the normal human conjunctiva and compared this with the distribution in the cornea, where IELs are not normally present. ${ }^{8,14}$

\section{METHODS}

Twelve tissue samples of human bulbar conjunctiva (9 samples) and cornea (3 samples) were obtained from 9 eye bank donor cadavers (Table I) within 8 hours of death. Specific, signed consent was obtained by the transplant coordinator from relatives for the tissue to be used in clinical research. Causes of death included brain glioma, myocardial infarct, carcinomatosis, cerebrovascular accident, pulmonary embolus and carcinoma of the bowel. The age of donors ranged from 10 to 82 years; none had active ocular disease.

\section{Frozen Sections}

The tissues were dissected and removed within 8 hours of death, transported in a sterile moist tube, maintained at $4{ }^{\circ} \mathrm{C}$ and processed for frozen sections within 12 hours. The corneal samples were mounted in OCT medium (Tissue-Tek), snap frozen in liquid nitrogen and stored at $-20^{\circ} \mathrm{C}$. Sheets of conjunctival tissue measuring approximately $10 \mathrm{~mm} \times 10 \mathrm{~mm}$ were spread on a tulle gauze surface with the epithelial surface upwards. The conjunctival sheets were wrapped around pieces of peeled cucumber, immersed in OCT medium and snap frozen in liquid nitrogen as described by Dua et al. ${ }^{15}$ Frozen sections were wrapped in aluminium foil and stored at $-20{ }^{\circ} \mathrm{C}$ until sectioning.

Cryosections of both tissues $6 \mu \mathrm{m}$ thick were cut using the Jung CM3000 system (Leica). Sections were mounted on superfrost precleaned slides and air-dried for 1 hour. These slides were stored at $-20{ }^{\circ} \mathrm{C}$ until staining. Immunostaining of the tissues was performed using the sensitive and simple avidin/ biotin alkaline phosphatase technique. Briefly, the cryostat sections (6 per specimen) were fixed in acetone for 10 minutes and allowed to air dry. The Ecadherin antigen specific mouse monoclonal primary antibody (Europath 5H9) was applied at a dilution of 1:20 for at least 1 hour, a 1:400 dilution of rabbit antimouse polyclonal antibody added for 30 minutes, and StrepAB Complex linked to alkaline phosphatase (Dako) used as the tertiary reagent. The slides were developed for 10-15 minutes in a solution of the chromagen Fast Red substrate (Dako). Trisbuffered normal saline ( $\mathrm{pH}$ 7.6) was used as wash buffer between steps and as a negative control. Antibody dilutions were made in the wash buffer. All slides were counterstained with Meyer's haematoxylin and mounted in free aqueous mountant. Positive red stained cells were observed under light microscopy. The positive control was from cryostat sections of normal human small bowel.

\section{Electron Microscopy}

One corneal and two conjunctival samples were each divided into three parts. The first part was fixed immediately for both scanning and transmission electron microscopy. The remaining two parts were de-epithelialised in ethylene diamino-tetra-acetic acid (EDTA). The EDTA was mixed to a concentration of $1 \mathrm{mmol}$ in $\mathrm{Ca}^{2+}$-free Hanks medium and adjusted to $\mathrm{pH}$ 7.4. The specimens were immersed for 30 minutes at $37^{\circ} \mathrm{C}$ and agitated in an orbital shaker. The EDTA/Hanks solution was changed and the procedure repeated twice to ensure complete deepithelialisation. One of the de-epithelialised

Table I. Summary of relevant patient data and results of immunostaining conjunctival and corneal sections for E-cadherin

\begin{tabular}{|c|c|c|c|c|c|c|c|}
\hline Patient no. & $\begin{array}{c}\text { Age } \\
\text { (years) }\end{array}$ & Sex & Tissue & Type of section & Primary cause of death & Ocular disease & Epithelial E-cadherin \\
\hline 1 & 10 & $\mathbf{M}$ & Conjunctiva & Frozen & Brain glioma & None & + ve \\
\hline 2 & 62 & $\mathbf{M}$ & $\begin{array}{l}\text { Conjunctiva } \\
\text { Intestine }\end{array}$ & $\begin{array}{l}\text { Frozen } \\
\text { Frozen }\end{array}$ & Myocardial infarct & None & $\begin{array}{l}+\mathrm{ve} \\
+\mathrm{ye}\end{array}$ \\
\hline 3 & 45 & $\mathbf{M}$ & Conjunctiva & Frozen & Carcinomatosis & None & $+\mathrm{ve}$ \\
\hline 4 & 76 & $\mathbf{M}$ & Conjunctiva & Frozen & Stroke & None & $+\mathrm{ve}$ \\
\hline 5 & 82 & $\mathrm{~F}$ & Conjunctiva & Frozen & Pulmonary embolus & None & $+\mathrm{ve}$ \\
\hline 6 & 73 & $\mathrm{~F}$ & Conjunctiva & Frozen & Bowel carcinoma & None & $+\mathrm{ve}$ \\
\hline 7 & 83 & $\mathbf{M}$ & $\begin{array}{l}\text { Conjunctiva } \\
\text { Cornea }\end{array}$ & $\begin{array}{l}\text { Frozen } \\
\text { Frozen }\end{array}$ & Carcinomatosis & None & $\begin{array}{l}+\mathrm{ve} \\
-\mathrm{ve}\end{array}$ \\
\hline 8 & 65 & $\mathrm{~F}$ & $\begin{array}{l}\text { Conjunctiva } \\
\text { Cornea }\end{array}$ & $\begin{array}{l}\text { Frozen } \\
\text { Frozen }\end{array}$ & Myocardial infarct & None & $\begin{array}{l}+\mathrm{ve} \\
-\mathrm{ve}\end{array}$ \\
\hline 9 & 71 & $\mathrm{~F}$ & $\begin{array}{l}\text { Conjunctiva } \\
\text { Cornea }\end{array}$ & $\begin{array}{l}\text { Frozen } \\
\text { Frozen }\end{array}$ & Myocardial infarct & None & $\begin{array}{l}+\mathrm{ve} \\
-\mathrm{ve}\end{array}$ \\
\hline
\end{tabular}




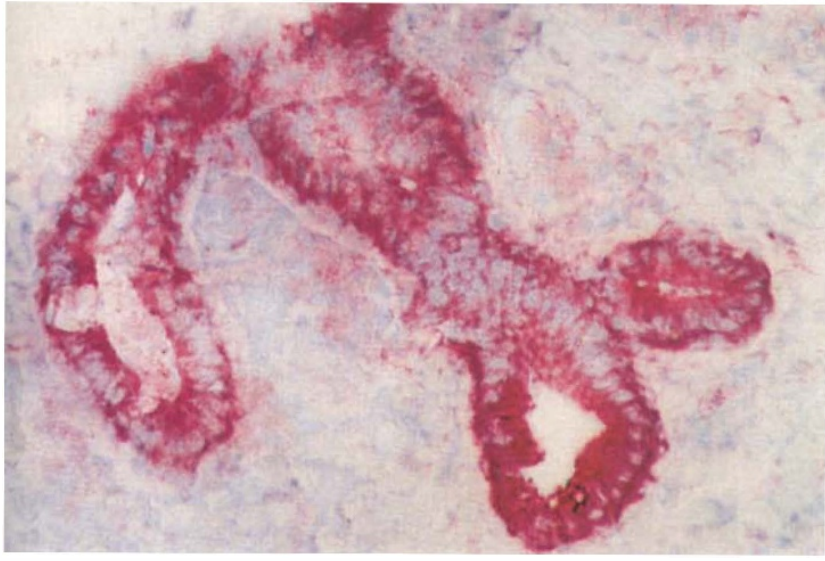

Fig. 1. Photomicrograph of a cryosection of human bulbar conjunctiva demonstrating positive immunohistochemical staining for E-cadherin in the epithelial layer $(\times 40)$.

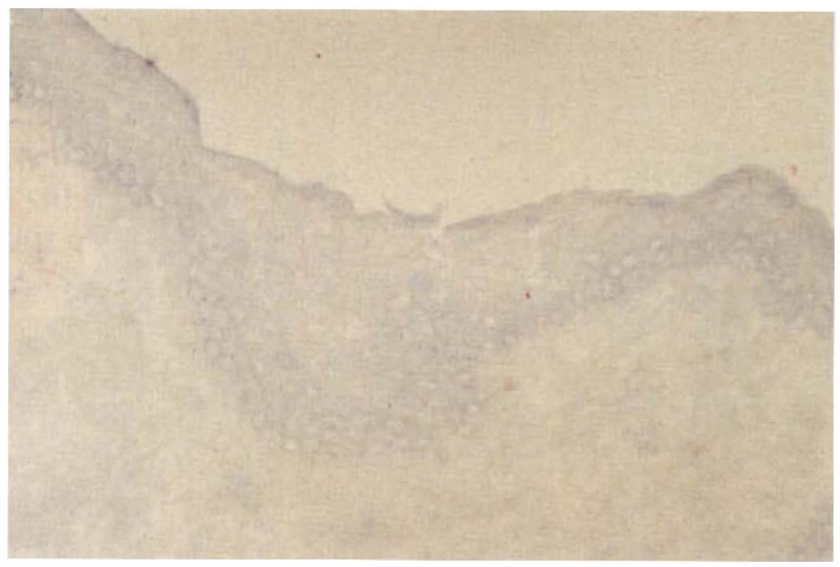

Fig. 2. Conjunctival negative control (cryosection, $\times 40$ ).

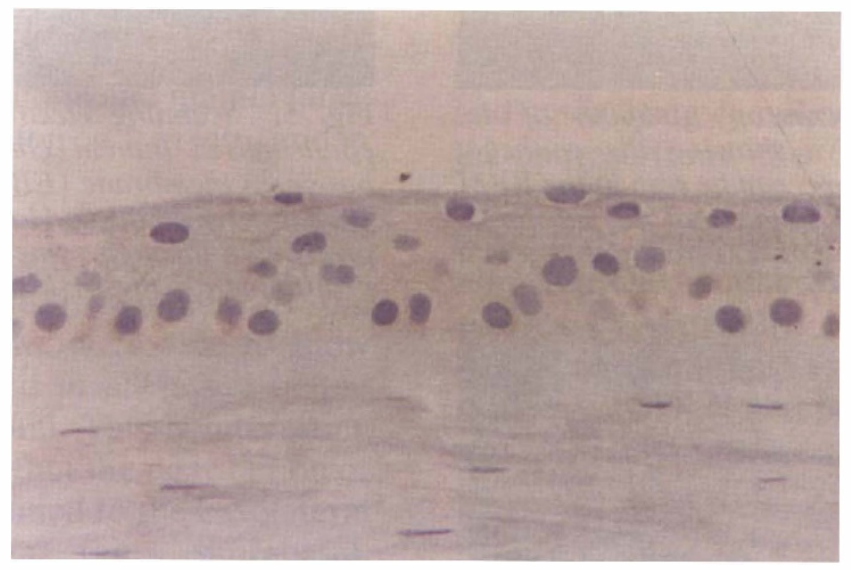

Fig. 3. Photomicrograph of human corneal cryosection with no staining for E-cadherin $(\times 40)$.

samples was fixed immediately for scanning electron microscopy. The remaining sample was incubated at $37^{\circ} \mathrm{C}$ in Eagle's culture medium for 24 hours and then fixed for scanning electron microscopy. The specimens were prepared for electron microscopy by immersion in $3 \%$ glutaraldehyde solution in $0.15 \mathrm{M}$ sodium cacodylate buffer ( $\mathrm{pH} 7.2$ ) at room temperature. Transmission and scanning electron microscopy were performed using standard techniques.

\section{Light Microscopy}

\section{RESULTS}

All the conjunctival test samples stained positively for E-cadherin (Fig. 1) compared with the negative controls (Fig. 2). Expression was confined to the conjunctival epithelium. All layers of the epithelium expressed E-cadherin. The distribution was strictly intercellular. The corneal epithelium did not stain for E-cadherin in either test samples (Fig. 3) or negative controls. The intestinal epithelium stained positively for E-cadherin and acted as a positive control.

\section{Electron Microscopy}

On scanning electron microscopy, pores were demonstrated in the conjunctival epithelial basement membrane (EBM). These were associated with areas of lymphocytic aggregation on the epithelial surface of the EBM. The underlying collagen matrix of the substantia propria could be seen through some of the pores, suggesting that they traverse the EBM (Fig. 4). Cells of probable lymphoid origin can be seen protruding from the substantia propria through some of the pores (Fig. 5). Transmission electron microscopy demonstrates full-thickness conjunctival EBM pores in cross-section. Cells of lymphocytic and macrophage morphology are often observed in the substantia propria immediately beneath the pores. In one view it appeared that an epithelial dendritic-type APC was immediately above a pore with an underlying lymphoid cell (possibly a lymphocyte) in the substantia propria (Fig. 6). The corneal EBM demonstrates the outlines of the epithelial cell attachments in a hexagonal mosaic pattern (Fig. 7). 


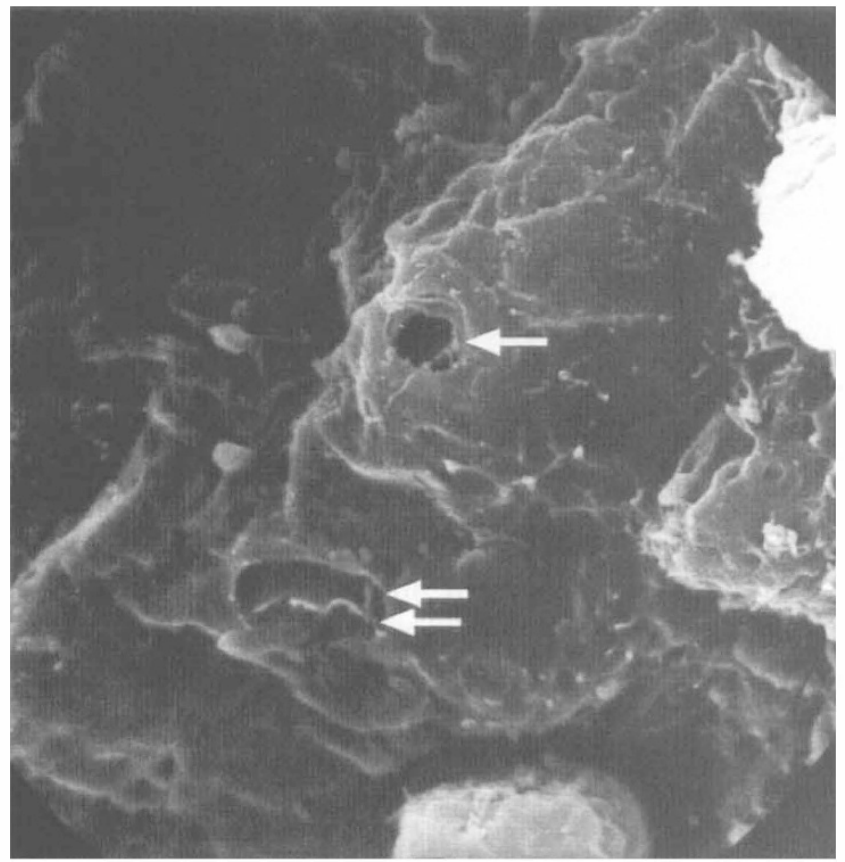

Fig. 4. Scanning electron microscopy $(\times 5000)$ of deepithelialised human conjunctiva showing the epithelial basement membrane (EBM). Pores can be seen in the EBM (arrow). The underlying collagen matrix of the substantia propria can be seen through one pore, proving that it is a full-thickness hole (double arrow).

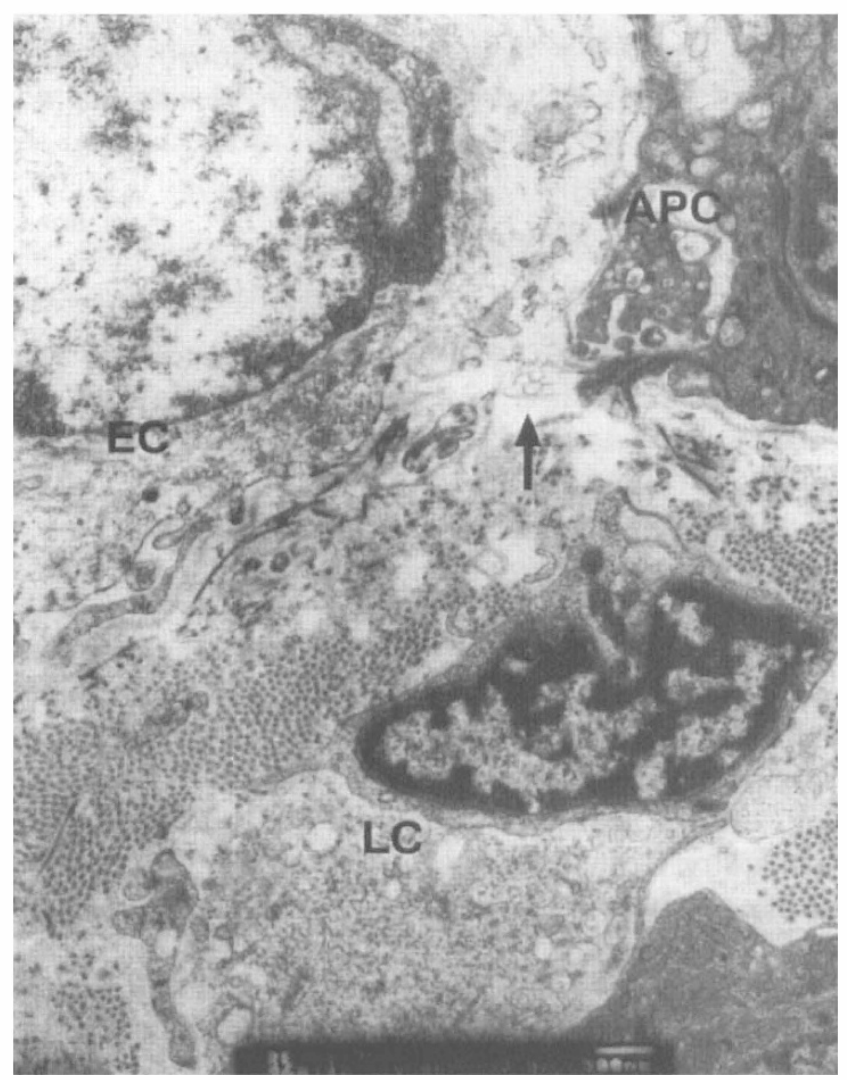

Fig. 6. Transmission electron microscopy (see scale) of human conjunctiva demonstrating a hole in the EBM (arrow). There is an underlying lymphoid cell (LC) in the substantia propria which is possibly a lymphocyte. Above the basement membrane is an epithelial cell (EC) and adjacent to the pore what appears to be an antigen presenting cell (APC) of dendritic morphology.

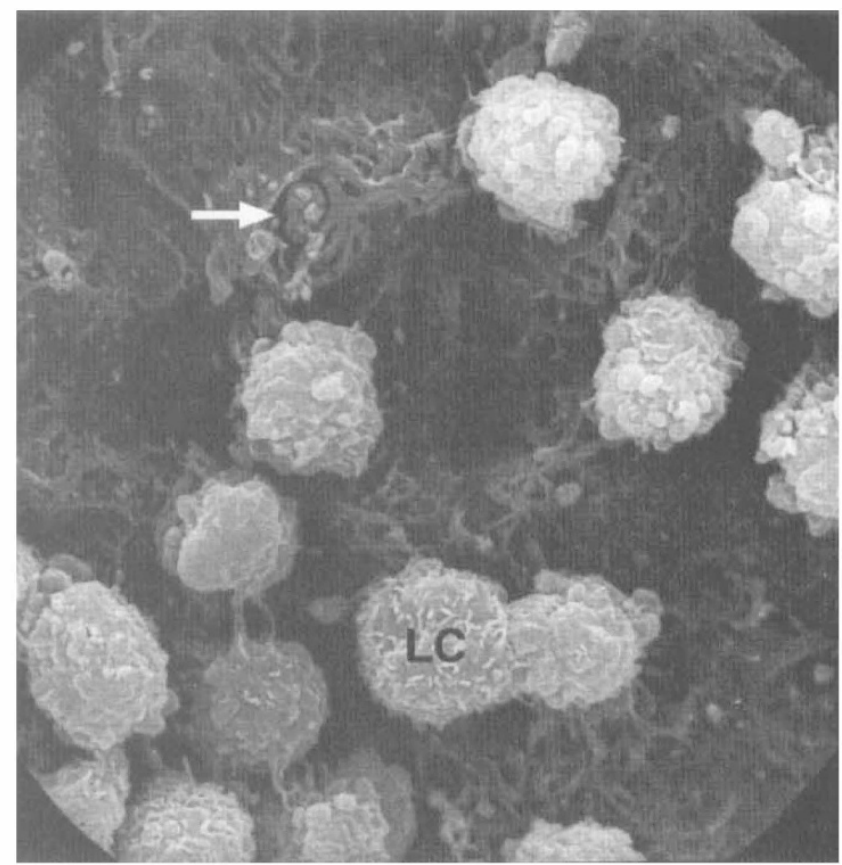

Fig. 5. Scanning electron microscopy $(\times 5000)$ of deepithelialised human conjunctiva showing the epithelial basement membrane (EBM). Pores are seen in an area of probable lymphocytic ( $L C)$ aggregation. Cells can be seen protruding through some of the pores from the substantia propria across the EBM (arrow).

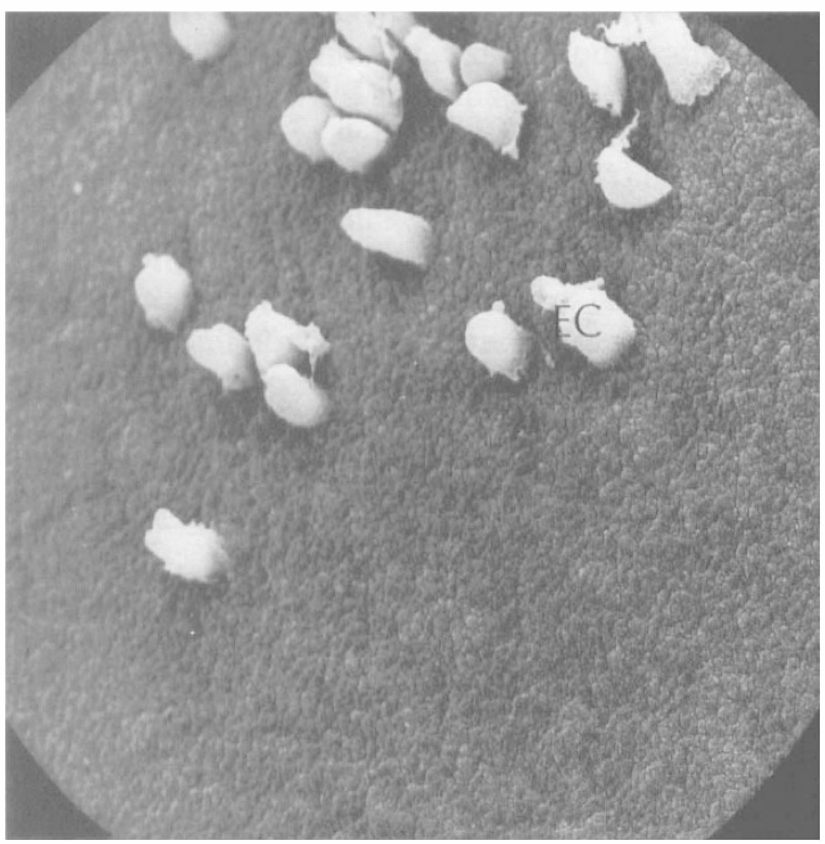

Fig. 7. Scanning electron microscopy of de-epithelialised cornea showing the epithelial basement membrane $(\times 600)$. There is a hexagonal mosaic pattern corresponding to epithelial cell attachments and a few remaining epithelial cells (EC). No pores are visible. 
There are no pores demonstrated on either scanning or transmission electron microscopy.

\section{DISCUSSION}

The cadherins are a family of transmembranous glycoprotein molecules that are essential for cell-cell adhesion. Cadherin activity has been detected on all cells forming solid tissues. ${ }^{16}$ Intercellular adhesion mediated by cadherins is calcium dependent. Depletion of calcium results in disruption of cell-cell cohesion. A similar effect has been observed with anti-cadherin antibodies. Over ten subclasses of cadherins, with distinct immunological specificities and tissue distribution, have been identified. ${ }^{17}$ All show a single transmembrane domain with a highly conserved intracellular cytoplasmic domain (carboxy-terminal) and an extracellular (amino-terminal) domain. E-cadherin (epithelial cadherin) primarily mediates cell-cell adhesion amongst epithelial cells and is also critical for the induction and maintenance of cell polarity and differentiation both in vitro and in adult epithelial tissues. ${ }^{18,19}$

E-cadherin is also known to be the ligand for an $\alpha_{E} \beta_{7}$ integrin (HML-1) expressed on IELs. IELs are anchored by HML-1/E-cadherin bonding to the epithelial cells. In this study we were able to show that E-cadherin was expressed in all layers of the conjunctival (bulbar) epithelium. This is interesting in the light of the observation that the distribution of IELs in the conjunctiva is confined to the basolateral surfaces of the basal, or at times suprabasal, epithelial cells. ${ }^{8}$ This implies that specific, possibly local, factors control the distribution of IELs preventing their spread throughout the epithelium. One explanation may be that the traffic of lymphocytes from lamina propria to the epithelial compartment may occur through the EBM. In this situation the lymphocytes may be arrested at the site where they first encounter their ligand (i.e. basal epithelial cells) and are therefore restricted to that site. Alternatively, apical desmosomal attachments between basal cells may present a barrier to anterior migration of lymphocytes. In conjunctival intraepithelial neoplasia (CIN) however, Dua et al. ${ }^{20}$ demonstrated the distribution of IELs through all layers of dysplastic epithelium and suggested that IELs may preferentially bind to dividing epithelial cells such as basal epithelial cells of normal conjunctiva or dysplastic cells of CIN. In the latter category, a disruption of desmosomal attachments may permit migration of lymphocytes through other layers of the epithelium.

Organ culture of conjunctiva in EDTA/Hanks medium resulted in complete de-epithelialisation of the conjunctiva, presumably by disruption of calcium-dependent, E-cadherin-mediated, intercellular bonds. Transfer of such de-epithelialised membranes to Eagle's culture medium allowed migration of lamina propria lymphocytes, across the EBM, on to the anterior surface of the denuded basement membrane. Electron microscopy studies of conjunctival EBM demonstrated multiple pores. These have not been previously described. They traverse the full thickness of the EBM and are related to areas of lymphoid aggregation on the epithelial surface. The pores are unlikely to be artefactual because they were present on transmission electron microscopy of normal conjunctiva and absent from the corneal EBM which had been de-epithelialised in exactly the same way. The APCs of the conjunctival epithelium are mostly dendritic and Langerhans cells. ${ }^{20-22}$ Communication with the substantia propria is likely to be through EBM pores. Lymphoid cells appear to protrude from the substantia propria of some of the pores. The transmission electron micrograph of Fig. 6 appears to demonstrate this mechanism with an epithelial APC in close proximity to an EBM pore and underlying lymphocyte. Cells migrate through the pores from the substantia propria to the epithelium. After de-epithelialisation, the EBM is devoid of cells beyond the occasional epithelial remnant. The lymphocytes observed on the epithelial surface of the EBM have migrated through the basement membrane. This is probably in response to the loss of epithelial cells. This situation supports the hypothesis that basal epithelial cells control lymphocytic migration into the epithelium. The transgression of cells could occur either through existing EBM pores or through new holes created by leucocytes by enzymatic digestion of basement membrane. A similar picture of EBM pores has been observed in the intestine; these are associated with lymphoid migration in response to de-epithelialisation and certain pathological states. ${ }^{23}$

The lack of pores in the corneal EBM has added significance if they are a route for lymphoid migration. Lymphoid migration to the corneal epithelium does not normally originate from underlying tissues but from the limbus inwards. There is no migration of cells across the corneal EBM and therefore no requirement for pores. The fact that E-cadherin (as detected by the antibody 5H9) is not found in the corneal epithelium may help explain why IEL are not normally found in this tissue. A modified form of E-cadherin is expressed in rabbit corneal epithelial cells. ${ }^{24}$ E-cadherin structure is conserved between species and it is possible that human corneal E-cadherin is different from that found in the conjunctiva. If so, this modified Ecadherin does not express a binding site for the HML-1 integrin or expose an epitope for the antibody 5H9. IELs could enter the corneal epithelium from the limbus but, without an anchoring HML-1/E-cadherin bond, they would readily leave 
the epithelial compartment. Antigen presenting Langerhans cells are known to be located maximally at the limbus and corneal periphery. ${ }^{21}$ This is in keeping with the concept that lymphocytes migrating through adjoining conjunctival basement membrane traverse to the limbus and peripheral cornea where they can communicate directly with APCs, rather than through EBM pores.

The data regarding conjunctival E-cadherin distribution presented in this study relate to bulbar conjunctiva, where HML- $1^{+} \mathrm{CD}^{+}$IELs have been shown to be maximally distributed. ${ }^{8}$ Further studies to elucidate its distribution in the fornicial and palpebral conjunctiva and within CIN are presently being undertaken.

This work was supported by a grant from the Royal College of Surgeons of Edinburgh.

Key words: Conjunctiva, Cornea, E-cadherin, Lymphocytes, Basement membrane.

\section{REFERENCES}

1. Holt PG, Sedgwick D. Suppression of responses following inhalation of antigen. Immunol Today 1987; 8:14-5.

2. Sedgwick JD, Holt PG. Down-regulation of immune responses to inhaled antigen: studies on the mechanism of induced suppression. Immunology 1985;56:635-42.

3. Strober W, James SP. The mucosal immune system. In: Sites DP, Terr AI, editors. Basic and clinical immunology, 7th ed. Englewood Cliffs, NJ: Appleton and Lange/Prentice-Hall, 1991:175-86.

4. Bienenstock J, Befus D. Gut and bronchus associated lymphoid tissue. Am J Anat 1983;170:437-45.

5. Fergusson A. Mucosal immunology. Immunol Today 1990;11:1-3.

6. Cerf-Bensussan N. Intestinal intraepithelial lymphocytes. Gastroenterol Clin North Am 1991;20:549-76.

7. Cepek KL, Shaw SK, Parker CM, Russell GJ, Morrow JS, Rimm DL, Brenner MB. Adhesion between epithelial cells and $\mathrm{T}$ lymphocytes mediated by $\mathrm{E}$ cadherin and the $\alpha_{E} \beta_{7}$ integrin. Nature 1994;372:190-3.

8. Dua HS, Gomes JAP, Jindal VK, Appa AN, Schwarting R, Eagle RC, Donoso LA, Laibson PR. Mucosa specific lymphocytes in the human conjunctiva, corneoscleral limbus and lacrimal gland. Curr Eye Res 1994;13:87-93.

9. Dua HS, Donoso LA, Laibson PR. Conjunctival instillation of retinal antigens induces tolerance. Ocular Immunol Inflamm 1994;2:29-36.
10. Egan RM, Stevens J, Yorkey CM, Black RG, Loh WK, Woodward JG. Murine conjunctival tolerance and the fate of antigen specific T-cells. Invest Ophthalmol Vis Sci 1996;37:235.

11. Dua HS, Jundal VK, Gomes JAP, Amoaku WM, Donoso LA, Laibson PR, Mahlberg K. The effect of topical cyclosporin on conjunctiva-associated lymphoid tissue (CALT). Eye 1996;10:433-8.

12. Gumbiner B, Simons K. The role of uvomorulin in the formation of epithelial occluding junctions. Symposium on junctional complexes of epithelial cells. London: Ciba Foundation, 1986:168-86.

13. Bock G, Clark S (eds). On the molecular organisation, diversity and functions of desmosomal proteins. Symposium on junctional complexes of epithelial cells. London: Ciba Foundation, 1986:5-9.

14. Scheiffarth OF, Stefani FH, Gabriel N, Lund OE. T lymphocytes of the normal human cornea. $\mathrm{Br} \mathrm{J}$ Ophthalmol 1987;71:384-6.

15. Dua HS, Gomes JAP, Singh A, Eagle RC, Donoso LA, Laibson PR. Fresh-frozen cucumber as a mount for conjunctival and corneal tissue in cryomicrotomy. Arch Ophthalmol 1994;112:1139-41.

16. Takeichi M. Cadherins: a molecular family important in selective cell-cell adhesion. Annu Rev Biochem 1990;59:237-52.

17. Shiozaki H, Oka H, Inoue M, Tamura S, Monden M. E-cadherin mediated adhesion system in cancer cells. Cancer 1996;77:1605-13.

18. Duband JL, Dufour S, Hatta K, Takeichi M, Edelman GM, Thiery JP. Adhesion molecules during somatogenesis in the avian embryo. J Cell Biol 1987; 104:1361-74.

19. Mareel M, Vleminckx K, Vermuelen S, Bracke M, Van Roy F. E-cadherin expression: a counterbalance for cancer cell invasion. Bull Cancer 1992;79:347-55.

20. Dua HS, Gomes JAP, Donoso LA, Laibson PR. The ocular surface as part of the mucosal immune system: conjunctival mucosa-specific lymphocytes in ocular surface pathology. Eye 1995;9:261-7.

21. Rodruigues MM, Rowden G, Hackett J, Bakos I. Langerhans cells in the normal conjunctiva and peripheral cornea of selected species. Invest Ophthalmol Vis Sci 1981;21:759-65.

22. Sacks EH, Wieczorek R, Jacobiek FA, Knowles DM. Lymphocytic subpopulation in the normal human conjunctiva: a monoclonal antibody study. Ophthalmology 1986;93:1276-83.

23. Mahida YR, Galvin A. Gray T, Makh S, McAlindon M, Sewell H, Podolsky DK. Migration of human intestinal lamina propria lymphocytes, macrophages and eosinophils following the loss of surface epithelial cells. Clin Exp Immunol 1997;109:377-86.

24. Mohan R, Lee B, Panjwani N. Molecular cloning and characterization of the rabbit corneal E-cadherin cDNA. Invest Ophthalmol Vis Sci 1995;36(Suppl):566. 